\title{
Entry and exit in hub-spoke networks
}

\author{
Ken Hendricks* \\ Michele Piccione* \\ and
}

Guofu Tan*

We offer an explanation for why regional carriers may not survive in hub-spoke networks. When a regional carrier and a hub operator compete in a spoke market, both will suffer losses in that market. But if the hub operator exits in the spoke market, its profits in connecting markets will fall. As long as the number of such markets is large enough, it is a dominant strategy for the hub operator not to exit from the spoke market. The regional carrier is then forced to exit, assuming fixed costs are not sunk.

\section{Introduction}

- Airline networks in the United States have undergone remarkable changes since the industry was deregulated in 1979. Given the freedom to choose their own route structure and prices, most airlines have transformed their networks into hub and spoke networks. Accompanying the emergence of hub-spoke networks has been a dramatic decline in interlining traffic (i.e., changing airlines at a connecting point). Bamberger and Carlton (1993) report that interlining traffic as a share of connecting traffic fell from $38.8 \%$ in 1979 to $4.5 \%$ in 1989 . This reflects the growth of single-carrier hub airports. Using a Herfindahl index to measure concentration at hub airports, Bamberger and Carlton conclude that concentration has increased by over $40 \%$ between 1983 and 1989. By 1989, single carriers controlled $60 \%$ or more of the traffic in 9 of the 21 hub airports.

The objective of this article is to explain why single-carrier hub-spoke networks are not invaded by regional carriers. One obvious explanation is that interlining is costly. Travelers may incur time costs in switching airlines at the hub airport, and airlines may experience coordination costs in arranging schedules and joint fares for connecting travelers. We offer an alternative explanation. We show that even if interlining is costless, the network externalities associated with a hub-spoke network make it difficult for regional carriers to survive.

* University of British Columbia; kenhen@unixg.ubc.ca; picc@econ.ubc.ca; gtan@unixg.ubc.ca.

This research has been financially supported by SSHRC-CANADA. We thank an anonymous referee for helpful comments. 
In a hub-spoke network with $n$ cities, the connecting flights that service a pair of nonhub cities are complementary goods. Nonhub travelers must purchase two tickets: one to fly from the nonhub city to the hub city and another to fly from the hub city to the destination city. If a regional carrier invades a spoke market and the hub operator does not concede the market, competition between the two carriers will lower prices in that market. The hub operator suffers losses in this market that it can partially offset by adjusting its prices on the complementary flights in $n-2$ connecting markets. If it concedes the spoke market, the hub operator does not suffer any losses in the spoke market, but it obtains lower profits in the associated connecting markets. When the size of the network is large enough, the latter effect dominates and the hub operator's optimal response to entry on a spoke is not to withdraw its flights from that spoke, even if the regional carrier threatens to stay. As a result, regional carriers are forced to exit and entry is deterred. Furthermore, this result holds even when city-pair markets are natural monopolies and fixed costs are not sunk (see also Bailey and Panzar (1981) on this issue).

The above argument is closely related to an argument due to Judd (1985). Judd was interested in explaining why investing first in a natural monopoly market may not be a barrier to entry. He pointed out that when an incumbent, multiproduct firm competes with an entrant in one of its markets, demands in markets for substitute goods fall. If fixed costs are not sunk and exit costs are low, the incumbent may want to withdraw its product and concede the market to the entrant. This in turn means that the potential entrant is not deterred by the incumbent firm's investment in a market and enters. The opposite conclusion is obtained when products are complements instead of substitutes. In that case, competition in one market can increase the incumbent's profits in markets where it is a monopolist. Furthermore, if the complementary relation is strong enough or the number of complementary products large enough, the optimal response of an incumbent to entry is not to withdraw its product, even if the entrant stays. Thus, complementarities among goods can be a barrier to entry.

There is a large and growing empirical literature on the airline industry. Much of it attempts to measure the effects of network characteristics and levels of competition on fares. Examples include Berry (1992), Berry, Carnall, and Spiller (1995), Borenstein (1989, 1990), Brueckner and Spiller (1994), Brueckner, Dyer, and Spiller (1992), Caves, Christensen, and Tretheway (1984), Kahn (1993), and Reiss and Spiller (1989). One of the main conclusions is that fares are relatively higher in hub markets, which may be evidence that the dominant carrier at hub airports is able to exploit its position to obtain monopoly rents in these markets. A recent survey of the literature can be found in Borenstein (1992). The theoretical literature on entry in airline networks is more sparse. Berechman and Shy (1993) study entry in a model with three cities and argue that a hub-spoke network is a more formidable barrier to entry than a point-to-point network. Oum, Zhang, and Zhang (1995) examine network choice in a duopoly model with three cities and show that hub-spoke networks have strategic advantages over point-to-point networks. Zhang (1996) studies a model in which two carriers are servicing the same pair of cities from different hub cities and one of the carriers invades the other carrier's spoke market.

The article is organized as follows. In Section 2 we present the model. Competition between a national and a regional carrier is formalized using a stylized game with three stages. Given the national carrier's choice of hub-spoke network, the regional carrier makes an entry decision in the first stage, both carriers simultaneously make exit decisions in the second stage, and they simultaneously choose prices in the final stage. In Section 3 we introduce the assumptions on demand and costs, which focuses the analysis on the case of spoke entry. In Section 4 we characterize equilibrium prices 
and exit behavior of the national carrier. In Section 5 we study optimal entry behavior of the regional carrier. Concluding remarks follow in Section 6.

\section{The model}

- There are $n$ cities, $n \geq 3$, and individuals living in each city who wish to travel to other cities. All travel is round trip. In what follows, the subscripts $g, h$ shall be used to index cities. There are two carriers that can provide air service to the cities, a national airline $(N)$ and a regional or commuter airline $(R)$. The national carrier is assumed to be operating a hub-spoke network. The regional carrier is assumed to have enough capital to supply nonstop air service for only one pair of cities.

We consider the subgame-perfect equilibria of a stylized dynamic game with three stages. In the first stage, the regional carrier has to decide whether to invade the hubspoke network of the national carrier by offering nonstop flights between the hub city and a nonhub city. In stage two, both carriers simultaneously make exit decisions. Finally, in stage three, both carriers compete for customers by simultaneously setting prices.

The costs of providing nonstop service between a pair of cities involve hiring station and ground site crews and investing in ticketing and promotion. These costs are independent of the total number of passengers travelling between the pair of cities and are denoted by $F$. A proportion $\gamma$ of $F$ is assumed to be sunk upon establishing nonstop service. That is, $(1-\gamma) F$ can be recovered if the carrier decides subsequently not to fly between the pair of cities. Thus, following the terminology from Judd (1985), $\gamma F$ is the entry cost, $(1-\gamma) F$ is the fixed production costs, and exit costs are zero. The cost of flying passengers nonstop between a pair of cities is proportional to the number of travelers. Let $c^{N}$ and $c^{R}$ denote, respectively, the national and regional carriers' marginal cost per traveller of a round trip on a direct flight. Then the marginal cost of servicing connecting travellers in city-pair markets serviced by the national carrier is $2 c^{N}$ and the marginal cost of servicing interlining travellers is $c^{N}+c^{R}$. Throughout this article we assume that $c^{R}$ cannot exceed $c^{N}$. A number of analysts have argued that regional carriers have lower operating costs than large national carriers due to lower wages and more intensive use of crews and planes.

Individuals who wish to travel from city $g$ to city $h$ are assumed to have no desire to travel anywhere else (i.e., no substitutability across city-pair markets). We also assume that individuals care only about reaching their destination at the lowest price, not how this destination is reached. In particular, they are indifferent to distance travelled, the number of stops incurred, and the airline that is flying them. Individuals differ in their willingness to pay, which is idiosyncratic and private. Demand in each city-pair market is the same. Hence, if $p$ is the price of the cheapest return ticket from city $g$ to city $h$, then the number of $g-h$ travelers is given by $D(p)$. The demand function is assumed to be strictly positive, downward sloping and differentiable.

Prices are based upon cities of origin and destination. Let $p_{g h}^{R}$ denote the price that the regional carrier charges $g-h$ customers for travelling on its flights. The price the national carrier charges $g-h$ customers depends upon how they travel. If they travel exclusively with the national carrier, then they pay $p_{g h}^{N}$. If they fly with both airlines (i.e., interline), then the cost of the trip is $p_{g h}^{R}+s_{g h}^{N}$, where $s_{g h}^{N}$ is the price charged by the national airline for its segment of the trip. For the remainder of the article we drop any reference to directional flows. That is, we impose the restriction that prices in the $(g-h)$ and $(h-g)$ markets are identical, so that the flows are also identical. This restriction simplifies the analytical expressions and is made without loss of generality. 


\section{Assumptions}

- Before conducting the analysis, we need to impose restrictions on demand and costs. Let $p_{M}\left(k c^{i}\right), i=N, R$, denote the monopoly price in a city-pair market where marginal costs are $k c^{i}$ and $\pi\left(k c^{i}\right)$ is the corresponding monopoly profits.

Assumption 1. $2 \pi\left(c^{R}\right)<F$.

Assumption 1 states that monopoly profits to a carrier (recall that $c^{N} \geq c^{R}$ ) from the direct traffic between two endpoint cities is not large enough to cover the fixed costs of supplying the pair of cities with nonstop service. To ensure profitability, the flights have to service other city-pair markets as well. It implies that the optimal monopoly network is a hub-spoke network (see Hendricks, Piccione, and Tan, 1995).

The next two assumptions impose regularity conditions on the demand function.

Assumption 2. $\epsilon(p)=-p D^{\prime}(p) / D(p)$ is nondecreasing in $p$.

Assumption 3. $D^{\prime}(p) / D(p)$ is strictly monotonic in $p$.

To understand the implications of these assumptions, consider the pricing decisions of the two carriers in a city-pair market that they service jointly. Each carrier $i$ chooses a price $p$ and obtains profits equal to $\left(p-c^{i}\right) D(p+s)$, given that the other carrier charges $s$ for its segment of the trip. Let $\phi^{i}(s)$ solve the first-order condition

$$
\left(p-c^{i}\right) D^{\prime}(p+s)+D(p+s)=0 .
$$

By definition, $\phi^{i}(0)$ is equal to the monopoly price. The following lemma states some properties of the best-reply function, $\phi^{i}(s)$.

Lemma 1. (i) $\phi^{i}(s)$ is single valued. (ii) If $D^{\prime}(p) / D(p)$ is strictly decreasing (increasing), then $\phi^{i}(s)$ is strictly decreasing (increasing) in $s$ for $i=N, R$.

Proof. Rewrite (1) as

$$
\epsilon(p+s)\left(p-c^{i}\right) /(p+s)=1 \text {. }
$$

Part (i) follows from (2) and Assumption 2 by noting that $\left(p-c^{i}\right) /(p+s)$ is strictly increasing in $p$. To prove part (ii), we first suppose that $D^{\prime}(p) / D(p)$ is strictly decreasing. The claim then follows easily, as $\phi^{i}(s)$ solves (1). Suppose next that $D^{\prime}(p) / D(p)$ is strictly increasing and that $s>s^{\prime}$ and $\phi^{i}(s) \leq \phi^{i}\left(s^{\prime}\right)$. Notice that (1) implies that $\phi^{i}(s)+s<\phi^{i}\left(s^{\prime}\right)+s^{\prime}$. A contradiction is then obtained from (2) and Assumption 2, since $\left(p-c^{i}\right) /(p+s)$ is strictly decreasing in $s$ and increasing in p. Q.E.D.

Lemma 1 implies that we can confine our analysis to two cases. In one case, both best replies are decreasing. Using the terminology of Bulow, Geanakoplos, and Klemperer (1985), the flights of the two carriers are strategic substitutes. ${ }^{1}$ In the other case, both best replies are increasing and the flights are strategic complements. ${ }^{2}$

Finally, we restrict the magnitude of the cost advantage of the regional carrier.

Assumption 4. (i) $\pi\left(c^{N}+c^{R}\right) / 2<\pi\left(2 c^{N}\right)$ if flights are strategic substitutes; (ii) $p_{M}\left(c^{R}\right)>c^{N}$ if flights are strategic complements.

${ }^{1}$ An example is given by $D(p)=1-p$. Some straightforward calculations reveal the monopoly price, $p_{M}\left(c^{N}\right)=\left(1+c^{N}\right) / 2$, and the best-response function, $\phi^{N}\left(p^{R}\right)=\left(1+c^{N}-p^{R}\right) / 2$.

${ }^{2}$ An example is given by $D(p)=p^{-\alpha}$, where $\alpha>1$. The monopoly price for the markets serviced by a direct connection is $p_{M}\left(c^{N}\right)=\alpha c^{N} /(\alpha-1)$, and the best-response function is $\phi^{N}\left(p^{R}\right)=$ $\alpha c^{N} /(\alpha-1)+p^{R} /(\alpha-1)$. 
The first condition states that in the case of strategic substitutes, the profit a national carrier obtains in a connecting market as a monopolist exceeds what it can obtain from servicing the market with a lower-cost regional carrier at the joint-profit-maximizing price and sharing the profits equally. Hence, the national carrier prefers not to share the market with the regional carrier. For strategic complements, Assumption 4 implies that marginal cost pricing by the national carrier prevents the regional carrier from charging its monopoly price.

\section{Equilibrium prices}

- There are three possible outcomes to the entry and exit stages. One outcome is that the regional carrier does not enter, in which case the national carrier operates the hub-spoke network as a monopolist. A second is that the regional carrier enters on a spoke and the national carrier drops its nonstop service between these two cities. A third is that the regional carrier enters and neither carrier exits. For each of these networks, we determine the equilibrium prices. The main analytical difficulty consists of identifying the intermarket pricing constraints and checking whether they are binding at equilibrium. These constraints reflect the fact that travellers have to be willing to identify themselves by purchasing their tickets in the appropriate city-pair market. In what follows, the hub city is labelled as city 1 and the nonhub city serviced by the regional carrier is labelled as city 2 .

Suppose the national carrier is a monopolist. At first glance, its optimization problem has a straightforward solution. It should charge $p_{M}\left(c^{N}\right)$ in each direct market and $p_{M}\left(2 c^{N}\right)$ in each connecting market. However, the carrier may not be able to charge these monopoly prices. One obvious constraint is that price in the direct market, the $(g-1)$ market, has to exceed prices in the corresponding connecting market, the $(g-h)$ markets, $g, h \neq 1$. Otherwise, $(g-1)$ travellers would have an incentive to purchase a $(g-h)$ ticket and deplane at the hub city. However, the carrier can stop this practice by requiring travellers to board their outgoing and return flights at the city designated on the ticket. This is indeed current practice among airlines. For this reason, we will ignore this constraint in our model.

A more substantive constraint concerns travellers flying between nonhub cities $g$ and $h$. Instead of purchasing a $(g-h)$ ticket, a $g-h$ traveller could fly into the hub city on a $(g-1)$ ticket and fly out on a $(1-h)$ ticket. To rule out this possibility, we impose the following constraint:

$$
p_{g 1}^{N}+p_{1 h}^{N} \geq p_{g h}^{N}, \quad \text { if } h \neq g, h, g \neq 1 .
$$

This constraint states that the sum of the prices in two direct markets has to be at least as great as the price of the corresponding connecting market.

The following lemma establishes that $(\mathrm{C} 1)$ is not binding at the monopoly prices given Assumption 2.

Lemma 2. Suppose the regional carrier does not enter. Then $p_{M}\left(2 c^{N}\right) \leq 2 p_{M}\left(c^{N}\right)$ and the national carrier's total profit is

$$
\Pi^{N}=2(n-1) \pi\left(c^{N}\right)+(n-1)(n-2) \pi\left(2 c^{N}\right)-(n-1) F .
$$

Proof. The first-order conditions for the unconstrained problem yield

$$
p_{g 1}\left(1-1 / \epsilon\left(p_{g 1}\right)\right)=c^{N} \text { and } p_{g h}\left(1-1 / \epsilon\left(p_{g h}\right)\right)=2 c^{N}
$$

First notice that since $\epsilon$ is nondecreasing, $p_{g h} \geq p_{g 1}$. From the first-order conditions we obtain 


$$
2 p_{g 1}\left(1-1 / \epsilon\left(p_{g 1}\right)\right)=p_{g h}\left(1-1 / \epsilon\left(p_{g h}\right)\right)
$$

Since $\epsilon$ is nondecreasing, the above equation implies that $p_{g h} \leq 2 p_{g 1}$. Q.E.D.

Suppose next that the regional carrier offers nonstop flights between cities 1 and 2. The possibility of interlining introduces further constraints on prices. We shall assume that the carriers can charge prices contingent on evidence that the traveller has purchased a ticket with the other carrier. This means that each carrier can charge hub travellers a higher price than interlining travellers. The latter have to purchase two tickets and are presumably willing to reveal that information if it means obtaining the tickets at lower prices. However, carriers cannot charge the interlining travellers more than hub travellers. Interlining travellers can always claim to have purchased only one ticket, and there is no message that hub travellers can give that would differentiate them from the interlining travellers.

More formally, we impose the following set of constraints:

$$
\begin{aligned}
p_{g 1}^{N}+p_{1 h}^{N} \geq p_{g h}^{N}, & \text { if } h \neq g, h, g \neq 1,2 \\
p_{g 1}^{N} \geq s_{g 2}^{N}, & \text { if } g=3, \ldots, n \\
p_{12}^{R} \geq p_{g 2}^{R}, & \text { if } g=3, \ldots, n .
\end{aligned}
$$

Now suppose the national carrier withdraws its nonstop service between cities 1 and 2. Each carrier is a monopolist in the city-pair markets for which it is the sole supplier. The two carriers jointly service the nonhub city-pair markets $(g-2), g=3, \ldots, n$, where demand is given by $D\left(s_{g 2}^{N}+p_{g 2}^{R}\right)$. Note that the connecting flights in each of these markets are perfect complements. Given the national carrier's prices, the regional carrier's payoff is

$$
2\left(p_{12}^{R}-c^{R}\right) D\left(p_{12}^{R}\right)+2 \sum_{g=3}^{n}\left(p_{g 2}^{R}-c^{R}\right) D\left(s_{g^{2}}^{N}+p_{g^{2}}^{R}\right)-F
$$

The first term represents the regional carrier's profits in the $(1-2)$ market, and the second term represents its profits in the $2(n-2)$ connecting markets that it services jointly with the national carrier. The regional carrier chooses its prices to maximize (3) subject to (C3) given the prices of the national carrier.

Similarly, the national carrier's payoff is

$$
\begin{gathered}
2 \sum_{g=3}^{n}\left(p_{g 1}^{N}-c^{N}\right) D\left(p_{g 1}^{N}\right)+2 \sum_{g=3}^{n}\left(s_{g 2}^{N}-c^{N}\right) D\left(s_{g^{2}}^{N}+p_{g 2}^{R}\right) \\
\quad+2 \sum_{h>g}^{n} \sum_{g=3}^{n}\left(p_{g h}^{N}-2 c^{N}\right) D\left(p_{g h}^{N}\right)-(n-2) F-\gamma F
\end{gathered}
$$

The first term represents the national carrier's profits in the $2(n-2)$ direct markets for which it is the sole supplier of air service. The second term represents its profits in the $2(n-2)$ connecting markets that it services jointly with the regional carrier, and the last term represents the $(n-2)(n-3)$ connecting markets in which it is the sole supplier of air service. It chooses its prices to maximize (4) subject to (C1a) and (C2) given the prices of the regional carrier.

The important feature of price equilibria in a shared hub-spoke network is that the regional carrier's price in every market exceeds the marginal costs of the national carrier. 
Lemma 3. Suppose the regional carrier offers nonstop service between cities 1 and 2 and the national carrier withdraws its nonstop service between these two cities. Then, in a Nash equilibrium, $p_{g 2}^{R}>c^{N}, g \neq 2$.

Proof. First consider the case of strategic complements. It follows from Lemma 1 that the best-reply functions are strictly increasing. Thus, in any Nash equilibrium, $p_{g^{2}}^{R} \geq p_{M}\left(c^{R}\right), g \neq 2$. The claim then follows from Assumption 4(ii).

In the case of strategic substitutes, constraints (C1a), (C2), and (C3) are not binding. Suppose that in a Nash equilibrium, $p_{g 2}^{R}=z$ for $g \neq 2$, where $z \in\left[c^{R}, c^{N}\right]$. Then, from the first-order conditions,

$$
\left(z-c^{R}\right) D^{\prime}\left(\phi^{N}(z)+z\right)+D\left(\phi^{N}(z)+z\right)=0
$$

and

$$
\left(\phi^{N}(z)-c^{N}\right) D^{\prime}\left(\phi^{N}(z)+z\right)+D\left(\phi^{N}(z)+z\right)=0 .
$$

Hence,

$$
\left(z-c^{R}\right) D\left(\phi^{N}(z)+z\right)=\left(\phi^{N}(z)-c^{N}\right) D\left(\phi^{N}(z)+z\right) \leq \pi\left(c^{N}+c^{R}\right) / 2 .
$$

Since $z \leq c^{N}$

$$
\left(\phi^{N}(z)-c^{N}\right) D\left(\phi^{N}(z)+z\right) \geq\left(\phi^{N}\left(c^{N}\right)-c^{N}\right) D\left(\phi^{N}\left(c^{N}\right)+c^{N}\right)=\pi\left(2 c^{N}\right),
$$

where the equality follows from $\phi^{N}\left(c^{N}\right)=p_{M}\left(2 c^{N}\right)-c^{N}$. This contradicts Assumption 4(i) and the claim follows. Q.E.D.

Although a complete description of price equilibria is not necessary to determine the optimal entry and exit decisions, it is interesting to note that the structure of equilibrium prices when flights in shared markets are strategic substitutes is quite different from when they are strategic complements. In the former case, the best-reply functions, $\phi^{i}, i=N, R$, are downward sloping, so the prices at their intersections are less than the monopoly prices, $p_{M}\left(c^{N}\right)$ and $p_{M}\left(c^{R}\right)$. (Recall that $\phi^{i}(0)=p_{M}\left(c^{i}\right)$.) Hence, $(\mathrm{C} 2)$ and (C3) are not binding. In the latter case, the best reply functions, $\phi^{i}, i=N, R$, are increasing, which implies that all of the constraints in (C2) are binding in equilibrium. The same is true for the constraints in (C3) if the price equilibrium is unique, that is, when the best-reply functions intersect only once. ${ }^{3}$ The result is that competition in the shared markets spills over into the direct markets. The national carrier cannot discriminate between $(g-2)$ and $(g-1)$ travellers and must charge both sets of travellers the same price. The regional carrier has to pool hub travellers with interlining travellers from at least one of the $n-2$ nonhub cities and charge each set the same price.

Finally, suppose the national carrier decides to compete with the regional carrier by maintaining nonstop flights between the hub city and city 2 . The two carriers offer perfect substitutes in the $(1-2)$ market. The one that offers the lower price wins the entire market at that price. The situation in nonhub $(g-2)$ markets is more complicated. The national carrier can service these markets by itself or share them with the regional carrier, depending upon whether it sets $p_{g 2}^{N}$ lower or higher than $p_{g 2}^{R}+s_{g 2}^{N}$. Define the indicator function

${ }^{3}$ If there are multiple price equilibria, prices can vary across $(g-2)$ connecting markets depending upon which price equilibrium is selected. The binding constraints in (C3) correspond to the connecting markets with the lowest equilibrium price. 


$$
\delta(x, y)= \begin{cases}1 & \text { if } x \leq y \\ 0 & \text { otherwise }\end{cases}
$$

We adopt the convention that if prices are the same in a $(g-2)$ market, then the regional carrier services all of the $(g-2)$ travellers flying between the hub city and city 2 . Then the payoff to the regional carrier is

$$
\begin{aligned}
& 2 \delta\left(p_{12}^{R}, p_{12}^{N}\right)\left(p_{12}^{R}-c^{R}\right) D\left(\min \left[p_{12}^{N}, p_{12}^{R}\right]\right) \\
& \quad+2 \sum_{g=3}^{n} \delta\left(s_{g 2}^{N}+p_{g 2}^{R}, p_{g 2}^{N}\right)\left(p_{g 2}^{R}-c^{R}\right) D\left(s_{g^{2}}^{N}+p_{g^{2}}^{R}\right)-F
\end{aligned}
$$

The regional carrier chooses its prices to maximize (5) subject to (C3) given the prices of the national carrier. The national carrier's payoff is

$$
\begin{aligned}
& 2\left[1-\delta\left(p_{12}^{R}, p_{12}^{N}\right)\right]\left(p_{12}^{N}-c^{N}\right) D\left(\min \left[p_{12}^{N}, p_{12}^{R}\right]\right) \\
& \quad+2 \sum_{g=3}^{n} \delta\left(s_{g 2}^{N}+p_{g 2}^{R}, p_{g 2}^{N}\right)\left(s_{g 2}^{N}-c^{N}\right) D\left(s_{g 2}^{N}+p_{g 2}^{R}\right) \\
& +2\left[1-\delta\left(s_{g 2}^{N}+p_{g 2}^{R}, p_{g 2}^{N}\right)\right]\left(p_{g 2}^{N}-2 c^{N}\right) D\left(p_{g 2}^{N}\right) \\
& \quad+2 \sum_{h>g}^{n} \sum_{g=3}^{n}\left(p_{g h}^{N}-2 c^{N}\right) D\left(p_{g h}^{N}\right)-(n-1) F
\end{aligned}
$$

It chooses its prices to maximize (6) subject to (C1) and (C2) given the prices of the regional carrier.

The following lemma establishes that the presence of a perfect substitute in the $(1-2)$ market implies that the regional carrier's price in every $(g-2)$ market cannot exceed $c^{N}$.

Lemma 4. Suppose the regional carrier offers nonstop service between cities 1 and 2 and the national carrier does not withdraw its nonstop service between these two cities. Then $p_{g 2}^{R} \leq c^{N}$ for $g \neq 2$.

Proof. We first show that $p_{g 2}^{R} \leq c^{N}$ for $g \neq 1$, 2. If $p_{g^{2}}^{R}>c^{N}$ for some $g \neq 1,2$, then $p_{g 2}^{N}<p_{g 2}^{R}+s_{g 2}^{N}$, since the national carrier can always obtain the entire $(g-2)$ market and increase its profits by lowering $p_{g 2}^{N}$. The constraints (C2) and (C3) imply that $p_{g 1}^{N}+p_{12}^{R} \geq s_{g 2}^{N}+p_{g 2}^{R}$. Thus, $p_{g 1}^{N}+p_{12}^{R}>p_{g 2}^{N}$. It follows that the national carrier can always undercut the regional carrier's price in the $(1-2)$ market without violating (C1). The regional carrier can also undercut the national carrier's price in the $(1-2)$ market and possibly make positive profits in the $(g-2)$ market setting $p_{g 2}^{R}=p_{12}^{R}$ to satisfy (C3). This implies that $p_{12}^{R} \leq c^{N}$ and a contradiction is obtained by (C3). Thus, $p_{g 2}^{R} \leq c^{N}$ for $g \neq 1,2$.

We now show that $p_{12}^{R} \leq c^{N}$. Suppose that $p_{12}^{R}>c^{N}$. We consider two cases. In the first case, $p_{12}^{N} \geq p_{12}^{R}$ and the national carrier makes zero profits in the $(1-2)$ market. If $p_{g 2}^{N} \leq p_{g 2}^{R}+s_{g 2}^{N}$, then it follows from (C2) and the above result that $p_{g 2}^{N} \leq c^{N}+p_{g 1}^{N}$. Thus, the national carrier can make positive profits by undercutting the regional carrier's price in the $(1-2)$ market without violating (C1). If $p_{g^{2}}^{N}>p_{g^{2}}^{R}+s_{g^{2}}^{N}$, set $p_{g^{2}}^{N}=p_{g_{2}}^{R}+s_{g_{2}}^{N}$ and repeat the above argument. In the second case, $c^{N} \leq p_{12}^{N}<p_{12}^{R}$. The regional carrier can increase profits by setting $p_{12}^{R}=p_{12}^{N}$ without violating (C3) since $p_{g^{2}}^{R} \leq c^{N}$. In both cases, a contradiction is obtained. Q.E.D. 
The next lemma provides a characterization of a set of equilibria in which the national carrier shares the nonhub $(g-2)$ market with the regional carrier and exploits the efficiency gains arising from lower costs. We will refer to these equilibria as accommodating equilibria.

Lemma 5. Suppose the regional carrier offers nonstop service between cities 1 and 2 . Then there exists a continuum of accomodating equilibria indexed by $z \in\left[c^{R}, c^{N}\right]$ in which the regional carrier charges $z$ for its flights, and the national carrier's prices are as follows:

$$
p_{12}^{N}=z, p_{g 2}^{N}=s(z)+z,\left(p_{g 1}^{N}, s_{g 2}^{N}\right)=(p(z), s(z)), g \neq 1,2,
$$

where

$$
\begin{aligned}
(p(z), s(z))= & \underset{s, p}{\operatorname{argmax}}\left\{\left(p-c^{N}\right) D(p)+\left(s-c^{N}\right) D(s+z)\right\} \\
& \text { subject to } s \leq p .
\end{aligned}
$$

\section{Proof. See the Appendix.}

The multiplicity of price equilibria described in Lemma 5 reflects an indeterminacy in the division of efficiency gains. The regional carrier is willing to accept any price between $c^{R}$ and $c^{N}$. Given our tie-breaking rule, the national carrier can enforce any such price by matching the regional carrier's price in the $(1-2)$ market and the joint fare in the nonhub $(g-2)$ market. At these prices, the regional carrier does not want to lower its price, since its profits would decline. If it raises its price, it would lose the markets and earn zero operating profits.

In the case of strategic substitutes, accommodating equilibria may not be the only equilibria. There may also exist a set of isolating equilibria in which the national carrier does not share any of the connecting $(g-2)$ markets by charging a high $s_{g^{2}}^{N}$ (details can be found in Hendricks, Piccione, and Tan (1994)).

\section{Equilibrium exit and entry}

- We turn now to the analysis of the exit and entry decisions. Consider first the exit decision of the national carrier. It follows from Lemmas 3 and 4 that the regional carrier's price in every $(g-2)$ market increases if the national carrier withdraws its nonstop service in the $(1-2)$ market. This causes profits of the national carrier to decline. The reduction is proportional to $(n-2)$, the number of connecting markets in which the carriers offer complementary flights. Clearly, $n$ does not have to be very large for the loss to exceed $(1-\gamma) F$, the recoverable part of fixed costs that the national carrier saves by withdrawing its nonstop service in the $(1-2)$ market. When this is the case, the national carrier does not want to discontinue its nonstop service in the hub market, even if the regional carrier does not exit.

Lemma 6. Suppose the regional carrier offers nonstop service between cities 1 and 2 . Then, for sufficiently large $n$, the national carrier never withdraws nonstop service between these two cities.

Consider next the exit decision of the regional carrier. The first point to note is that Lemmas 4 and 6 imply that for sufficiently large $n$, the regional carrier can earn positive profits upon entry only if it enjoys a cost advantage. This yields the following conclusion. 
Proposition 1. Suppose $c=c^{R}=c^{N}$. Then for sufficiently large $n$, the unique subgameperfect outcome consists of the regional carrier not entering and the national carrier operating a monopoly hub-spoke network.

If the regional carrier has a marginal cost advantage, Lemma 6 leads to the following conclusion.

Proposition 2. Suppose $c^{R}<c^{N}$. Then there is a set of equilibria in which, for sufficiently large $n$, the regional carrier enters on a spoke and neither carrier exits.

Proof. Recall that Lemma 6 implies that the national carrier never exits for $n$ sufficiently large. Consider an accommodating equilibrium in which the regional carrier charges $z$ such that $c^{N} \geq z>c^{R}$. In such an equilibrium, the regional carrier's profits from operating are

$$
\Pi^{R}=2\left(z-c^{R}\right) D(z)+2(n-2)\left(z-c^{R}\right) D(z+s(z)) .
$$

If it exits, it recovers a portion $(1-\gamma) F$ of its entry cost. Therefore, given any $z>c^{R}$ and $n$ sufficiently large, the optimal decision is not to exit. It should enter whenever $\Pi^{R}>F$. Q.E.D.

We conclude this section by noting that the multiplicity of accommodating equilibria can be eliminated with a refinement of Nash equilibrium such as "tremblinghand" perfection. This solution concept requires strategies to be robust to trembles in the opponent strategies. In the $(1-2)$ market, the national carrier is willing to match the regional carrier's price when it is less than $c^{N}$ only because it does not have to transport any travellers between the hub city and city 2 at this price. This strategy is not a best response if there is any chance that the regional carrier would make a "mistake" and charge a higher price than what is called for in equilibrium. Instead, the best response would be to charge $c^{N}$. A similar argument eliminates equilibria in which the regional carrier prices below $c^{N}$ in the other $(g-2)$ markets. ${ }^{4}$ Thus, the "trembling-hand" perfect equilibrium gives all the efficiency gains to the regional carrier.

\section{Conclusion}

- We have shown that the complementarities associated with a hub-spoke network can deter regional carriers from entering. The reason is that the hub operator can credibly threaten to maintain its presence in a spoke market even when it suffers losses in that market due to competition. As a result, regional carriers that do not have a cost advantage are forced to exit, and entry is deterred. The situation is more ambiguous when the regional carrier has a significant cost advantage. In that case, there are equilibria in which the hub operator accommodates the lower-cost entrant and shares in the efficiency gains.

Levine (1987) cites a 1986 report by Pickrell and Oster suggesting that major airlines and regional carriers have often pursued an alternative to competition. They report that by 1986 , virtually all the commuter and regional airlines were tied contractually to one of the major airlines operating hub-and-spoke networks. In our context, the motivation for these agreements is to exploit efficiency gains, with the carriers' relative ability to compete in a spoke market constituting an important determinant of the division of these gains. Regional carriers with no cost advantage would be forced to exit.

\footnotetext{
4 "Trembling-hand" perfection also eliminates the set of isolating equilibria.
} 
A number of airlines such as Southwest Airlines, Reno Air, and Morris Air have invaded hub-and-spoke networks by entering on the "rim." This strategy is feasible when the direct traffic between two nonhub cities can generate enough operating profits to cover the fixed costs of a direct connection. The national carrier services the nonhub city-pair market at a marginal cost of $2 c^{N}$, whereas the regional carrier can service the market at a marginal cost of $c^{R}$. So even if carriers have identical marginal costs, the regional carrier can make positive operating profits. But the volume of direct traffic has to be relatively large, since the flights do not carry any connecting travellers.

\section{Appendix}

- Proof of Lemma 5. The following lemmas are useful.

Lemma A1. Suppose that Assumption 2 holds and $p^{*}$ maximizes

$$
f(p)=(p-c)(\alpha D(p)+D(p+z)), \alpha, z \geq 0 \quad \text { and } \quad c>0 .
$$

(i) If $\alpha=0$, then $f^{\prime}(p)>0$ for $p<p^{*}$ and $f^{\prime}(p)<0$ for $p>p^{*}$.

(ii) If $\alpha>0$ and $D^{\prime}(p) / D(p)$ is strictly increasing, then $f^{\prime}(p)>0$ for $p<p^{*}$ and $f^{\prime}(p)<0$ for $p>p^{*}$.

Proof. Suppose $\alpha=0$. Then $f^{\prime}(p)=D(p+z)[1-\epsilon(p+z)(p-c) /(p+z)]$ and $p^{*}$ satisfies the first-order condition

$$
1-\epsilon\left(p^{*}+z\right)\left(p^{*}-c\right) /\left(p^{*}+z\right)=0 .
$$

Assumption 2 implies that $1-\epsilon(p+z)(p-c) /(p+z)>1-\epsilon\left(p^{*}+z\right)\left(p^{*}-c\right) /\left(p^{*}+z\right)=0$ for $p<p^{*}$ and $1-\epsilon(p+z)(p-c) /(p+z)<1-\epsilon\left(p^{*}+z\right)\left(p^{*}-c\right) /\left(p^{*}+z\right)=0$ for $p>p^{*}$. Claim (i) follows.

Suppose $\alpha>0$. Then

$$
f^{\prime}(p)=D(p+z)[(1-\epsilon(p)(p-c) / p) \alpha D(p) / D(p+z)+1-\epsilon(p+z)(p-c) /(p+z)]
$$

and $p^{*}$ satisfies the first-order condition

$$
\left(1-\epsilon\left(p^{*}\right)\left(p^{*}-c\right) / p^{*}\right) \alpha D\left(p^{*}\right) / D\left(p^{*}+z\right)+1-\epsilon\left(p^{*}+z\right)\left(p^{*}-c\right) /\left(p^{*}+z\right)=0 .
$$

Since $D^{\prime}(p) / D(p)$ is strictly increasing, it follows that $D(p) / D(p+z)$ is strictly decreasing in $p$. Then Assumption 2 implies that

$$
\begin{aligned}
& (1-\epsilon(p)(p-c) / p) \alpha D(p) / D(p+z)+1-\epsilon(p+z)(p-c) /(p+z) \\
& \quad>\left(1-\epsilon\left(p^{*}\right)\left(p^{*}-c\right) / p^{*}\right) \alpha D\left(p^{*}\right) / D\left(p^{*}+z\right)+1-\epsilon\left(p^{*}+z\right)\left(p^{*}-c\right) /\left(p^{*}+z\right)=0
\end{aligned}
$$

for $p<p^{*}$. An analogous argument shows that $f^{\prime}(p)<0$ for $p>p^{*}$. Q.E.D.

Lemma A2. Suppose $D^{\prime}(p) / D(p)$ is strictly decreasing and $\pi\left(c^{N}+c^{R}\right)<2 \pi\left(2 c^{N}\right)$. Then

$$
\left(z-c^{R}\right) D^{\prime}\left(\phi^{N}(z)+z\right)+D\left(\phi^{N}(z)+z\right)>0 \text { for } z \in\left[c^{R}, c^{N}\right] .
$$

Proof. Suppose $\left(z-c^{R}\right) D^{\prime}\left(\phi^{N}(z)+z\right)+D\left(\phi^{N}(z)+z\right) \leq 0$ for some $z \in\left[c^{R}, c^{N}\right]$. Since $D(p)^{\prime} / D(p)$ is strictly decreasing, it follows from the definition of $\phi^{N}(z)$ that $z-c^{R} \geq \phi^{N}(z)-c^{N}$. Thus,

$$
\left(z-c^{R}\right) D\left(\phi^{N}(z)+z\right) \geq\left(\phi^{N}(z)-c^{N}\right) D\left(\phi^{N}(z)+z\right) \geq \pi\left(2 c^{N}\right) .
$$

This contradicts the assumption $\pi\left(c^{N}+c^{R}\right)<2 \pi\left(2 c^{N}\right)$. Q.E.D.

Notice that if flights are strategic substitutes, Lemmas A1 and A2 imply that $\phi^{R}\left(\phi^{N}\left(c^{N}\right)\right)>c^{N}$. Since $\phi^{R}(0) \geq \phi^{R}\left(\phi^{N}\left(c^{N}\right)\right)$ and $\phi^{R}(0)=p_{M}\left(c^{R}\right)$, it follows that $p_{M}\left(c^{R}\right)>c^{N}$. We now prove Lemma 5 .

Proof of Lemma 5. Consider an accommodating equilibrium where $p_{g^{2}}^{R}=z$ if $g \neq 2, c^{R} \leq z \leq c^{N}$. We now compute the best replies of the national carrier. We first show that $p_{12}^{N}=z$ is a best reply. If the national carrier raises this price, its demand in the $(1-2)$ market remains equal to zero and all the other markets 
are not affected. If the price is decreased, the national carrier becomes the sole supplier in that market. However, profits in the $(1-2)$ market become negative and profits in all the other markets cannot increase, as the constraints in $(\mathrm{C} 1)$ are tighter. Thus, $p_{12}^{N}=z$ is a best response.

We now consider connecting markets. If the national carrier shares a $(g-2)$ connecting market with the regional carrier, it chooses $p_{g 1}^{N}$ and $s_{g^{2}}^{N}$ to maximize

$$
\left(p_{g_{1}}^{N}-c^{N}\right) D\left(p_{g 1}^{N}\right)+\left(s_{g^{2}}^{N}-c^{N}\right) D\left(s_{g^{2}}^{N}+z\right)
$$

subject to $p_{g^{1}}^{N} \geq s_{g 2}^{N}$. This is equivalent to choosing $p_{g 1}^{N}$ and $q$ to maximize

$$
\left(p_{g 1}^{N}-c^{N}\right) D\left(p_{g 1}^{N}\right)+\left(q-c^{N}-z\right) D(q)
$$

subject to $p_{g 1}^{N}+z \geq q$. maximize

If the national carrier is a monopolist in the $(g-2)$ connecting market, it chooses $p_{g^{1}}^{N}$ and $p_{g^{2}}^{N}$ to

$$
\left(p_{g 1}^{N}-c^{N}\right) D\left(p_{g 1}^{N}\right)+\left(p_{g 2}^{N}-2 c^{N}\right) D\left(p_{g 2}^{N}\right)
$$

subject to $p_{g 1}^{N}+z \geq p_{g 2}^{N}$.

Since $z \leq c^{N}$, the first optimization problem yields profits at least as high as those obtained in the second problem. Thus it is always optimal for the national carrier to share the $(g-2)$ connecting market. It follows that $\left(p_{g 1}^{N}, s_{g 2}^{N}\right)=(p(z), s(z))$ if $g=3, \ldots, n$, and $p_{g 2}^{N}=s(z)+z$ are best replies. Finally, $p_{g h}^{N}=p_{M}\left(2 c^{N}\right)$ for $h, g=3, \ldots, n, h \neq g$. Notice that in the case of strategic substitutes $p(z)=p_{M}\left(c^{N}\right)$ and in the case of strategic complements $p(z)>p_{M}\left(c^{N}\right)$. Lemma 2 then implies that (C1) is satisfied.

To verify that $p_{g^{2}}^{R}=z$, if $g \neq 2$, are best replies, first notice that if the regional carrier chooses higher prices, the demand falls to zero. Thus, we only have to show that the regional carrier does not have an incentive to choose lower prices. The objective of the regional carrier is to choose its prices to maximize

$$
2\left(p_{12}^{R}-c^{R}\right) D\left(p_{12}^{R}\right)+2 \sum_{g=3}^{n}\left[\left(p_{g^{2}}^{R}-c^{R}\right) D\left(s(z)+p_{g^{2}}^{R}\right)\right]
$$

subject to $p_{g 2}^{R} \leq p_{12}^{R} \leq z, g=3, \ldots, n$.

If flights are strategic complements, Lemma Al and Assumption 4(ii) imply that $p_{12}^{R}=z$. Otherwise, $p_{12}^{R}<z$ and

$$
\left(p_{12}^{R}-c^{R}\right) D^{\prime}\left(p_{12}^{R}\right)+D\left(p_{12}^{R}\right) \leq 0,
$$

which contradicts Assumption 4(ii) and Lemma A1. Since $\phi^{R}$ is increasing, a similar argument establishes that $p_{g^{2}}^{R}=z, g=3, \ldots, n$.

If flights are strategic substitutes, then $s(z)=\phi^{N}(z)$. By the remark following Lemma $\mathrm{A} 2, p_{M}\left(c^{R}\right)>c^{N}$. Hence, Lemma A1 implies that $p_{12}^{R}=z$. To show that $p_{g^{2}}^{R}=z$, by Lemma A1 it is sufficient to show that

$$
\left(z-c^{R}\right) D^{\prime}(s(z)+z)+D(s(z)+z)>0
$$

which follows by Lemma A2. Q.E.D.

\section{References}

Bailey, E. And Panzar, J.C. "The Contestability of Airline Markets During the Transition to Deregulation." Law and Contemporary Problems, Vol. 44 (1981), pp. 125-145.

Bamberger, G. And Carlton, D.W. "Airline Networks and Fares.” Mimeo, University of Chicago, 1993.

Berechman, J. And Shy, O. "Airline Deregulation and the Choice of Networks." Mimeo, Public Policy and Economics Department, Tel-Aviv University, 1993.

BERRY, S. "Estimation of a Model of Entry in the Airline Industry." Econometrica, Vol. 60 (1992), pp. 889917.

Berry, S., Carnall, M., And SpIller, P.T. “Airline Hubs: Cost and Demand." Mimeo, Yale University, 1995.

BorensteIn, S. "Hubs and High Fares: Dominance and Market Power in the U.S. Airline Industry." RAND Journal of Economics, Vol. 20 (1989), pp. 344-365. 
—. "Airline Mergers, Airport Dominance, and Market Power." American Economic Review, Vol. 80 (1990), pp. 400-404.

. "The Evolution of U.S. Airline Competition." Journal of Economic Perspectives, Vol. 6 (1992), pp. 45-73.

BRUECKNER, J.K. AND SPILlER, P.T. "Economies of Traffic Density in the Deregulated Airline Industry." Journal of Law and Economics, Vol. 37 (1994), pp. 379-415.

- DYER, N.J., AND SPILlER, P.T. "Fare Determination in Airline Hub-and-Spoke Networks." RAND Journal of Economics, Vol. 23 (1992), pp. 309-333.

Bulow, J., Geanakoplos, J., AND KLemPeRer, P. "Multimarket Oligopoly: Strategic Substitutes and Complements." Journal of Political Economy, Vol. 93 (1985), pp. 488-511.

Caves, D., Christensen, L., And Tretheway, M. "Economies of Density Versus Economies of Scale: Why Trunk and Local Service Airline Costs Differ." RAND Journal of Economics, Vol. 15 (1984), pp. 471489.

Hendricks, K., Piccione, M., And Tan, G. "Entry and Exits in Hub-Spoke Networks.” Mimeo, Department of Economics, University of British Columbia, 1994.

- - AND - "The Economics of Hubs: The Case of Monopoly." Review of Economic Studies, Vol. 62 (1995), pp. 83-99.

JUDD, K. “Credible Spatial Preemption." RAND Journal of Economics, Vol. 16 (1985), pp. 153-166.

KAHN, A.E. "The Competitive Consequences of Hub Dominance: A Case Study." Review of Industrial Organization, Vol. 8 (1993), pp. 381-405.

LeVINE, M. "Airline Competition in Deregulated Markets: Theory, Firm Strategy, and Public Policy." Yale Journal of Regulation, Vol. 4 (1987), pp. 393-494.

Oum, T.H., ZhANG, A., AND ZHANG, Y. “Airline Network Rivalry.” Canadian Journal of Economics, Vol. 28 (1995), pp. 836-857.

ReISS, P. AND SPILlER, P. "Competition and Entry in Small Airline Markets." Journal of Law and Economics, Vol. 32 (1989), pp. S179-S202.

ZhANG, A. "An Analysis of Fortress Hubs in Airline Networks." Mimeo, Department of Economics, University of Victoria, 1996. 
http://www.jstor.org

\title{
LINKED CITATIONS
}

\author{
- Page 1 of 3 -
}

You have printed the following article:

Entry and Exit in Hub-Spoke Networks

Ken Hendricks; Michele Piccione; Guofu Tan

The RAND Journal of Economics, Vol. 28, No. 2. (Summer, 1997), pp. 291-303.

Stable URL:

http://links.jstor.org/sici?sici=0741-6261\%28199722\%2928\%3A2\%3C291\%3AEAEIHN\%3E2.0.CO\%3B2-M

This article references the following linked citations. If you are trying to access articles from an off-campus location, you may be required to first logon via your library web site to access JSTOR. Please visit your library's website or contact a librarian to learn about options for remote access to JSTOR.

\section{References}

The Contestability of Airline Markets during the Transition to Deregulation

Elizabeth E. Bailey; John C. Panzar

Law and Contemporary Problems, Vol. 44, No. 1, Managing the Transition to Deregulation.

(Winter, 1981), pp. 125-145.

Stable URL:

http://links.jstor.org/sici?sici=0023-9186\%28198124\%2944\%3A1\%3C125\%3ATCOAMD\%3E2.0.CO\%3B2-V

\section{Estimation of a Model of Entry in the Airline Industry}

Steven T. Berry

Econometrica, Vol. 60, No. 4. (Jul., 1992), pp. 889-917.

Stable URL:

http://links.jstor.org/sici?sici=0012-9682\%28199207\%2960\%3A4\%3C889\%3AEOAMOE\%3E2.0.CO\%3B2-F

\section{Hubs and High Fares: Dominance and Market Power in the U.S. Airline Industry}

Severin Borenstein

The RAND Journal of Economics, Vol. 20, No. 3. (Autumn, 1989), pp. 344-365.

Stable URL:

http://links.jstor.org/sici?sici=0741-6261\%28198923\%2920\%3A3\%3C344\%3AHAHFDA\%3E2.0.CO\%3B2-4 
http://www.jstor.org

\title{
LINKED CITATIONS
}

- Page 2 of 3 -

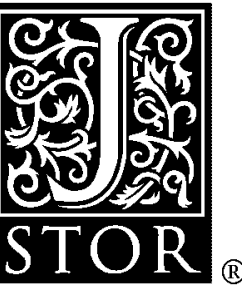

\begin{abstract}
Airline Mergers, Airport Dominance, and Market Power
Severin Borenstein

The American Economic Review, Vol. 80, No. 2, Papers and Proceedings of the Hundred and Second Annual Meeting of the American Economic Association. (May, 1990), pp. 400-404.

Stable URL:

http://links.jstor.org/sici?sici=0002-8282\%28199005\%2980\%3A2\%3C400\%3AAMADAM\%3E2.0.CO\%3B2-L
\end{abstract}

\section{The Evolution of U.S. Airline Competition}

Severin Borenstein

The Journal of Economic Perspectives, Vol. 6, No. 2. (Spring, 1992), pp. 45-73.

Stable URL:

http://links.jstor.org/sici?sici=0895-3309\%28199221\%296\%3A2\%3C45\%3ATEOUAC\%3E2.0.CO\%3B2-6

\section{Economies of Traffic Density in the Deregulated Airline Industry}

Jan K. Brueckner; Pablo T. Spiller

Journal of Law and Economics, Vol. 37, No. 2. (Oct., 1994), pp. 379-415.

Stable URL:

http://links.jstor.org/sici?sici=0022-2186\%28199410\%2937\%3A2\%3C379\%3AEOTDIT\%3E2.0.CO\%3B2-V

\section{Fare Determination in Airline Hub-and-Spoke Networks}

Jan K. Brueckner; Nichola J. Dyer; Pablo T. Spiller

The RAND Journal of Economics, Vol. 23, No. 3. (Autumn, 1992), pp. 309-333.

Stable URL:

http://links.jstor.org/sici?sici=0741-6261\%28199223\%2923\%3A3\%3C309\%3AFDIAHN\%3E2.0.CO\%3B2-T

\section{Multimarket Oligopoly: Strategic Substitutes and Complements}

Jeremy I. Bulow; John D. Geanakoplos; Paul D. Klemperer

The Journal of Political Economy, Vol. 93, No. 3. (Jun., 1985), pp. 488-511.

Stable URL:

http://links.jstor.org/sici?sici=0022-3808\%28198506\%2993\%3A3\%3C488\%3AMOSSAC\%3E2.0.CO\%3B2-D

Economies of Density versus Economies of Scale: Why Trunk and Local Service Airline Costs Differ

Douglas W. Caves; Laurits R. Christensen; Michael W. Tretheway

The RAND Journal of Economics, Vol. 15, No. 4. (Winter, 1984), pp. 471-489.

Stable URL:

http://links.jstor.org/sici?sici=0741-6261\%28198424\%2915\%3A4\%3C471\%3AEODVEO\%3E2.0.CO\%3B2-S 
http://www.jstor.org

\section{LINKED CITATIONS \\ - Page 3 of 3 -}

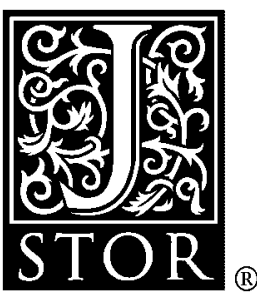

\section{The Economics of Hubs: The Case of Monopoly}

Ken Hendricks; Michele Piccione; Guofu Tan

The Review of Economic Studies, Vol. 62, No. 1. (Jan., 1995), pp. 83-99.

Stable URL:

http://links.jstor.org/sici?sici=0034-6527\%28199501\%2962\%3A1\%3C83\%3ATEOHTC\%3E2.0.CO\%3B2-5

\section{Credible Spatial Preemption}

Kenneth L. Judd

The RAND Journal of Economics, Vol. 16, No. 2. (Summer, 1985), pp. 153-166.

Stable URL:

http://links.jstor.org/sici?sici=0741-6261\%28198522\%2916\%3A2\%3C153\%3ACSP\%3E2.0.CO\%3B2-D

\section{Airline Network Rivalry}

Tae Hoon Oum; Anming Zhang; Yimin Zhang

The Canadian Journal of Economics / Revue canadienne d'Economique, Vol. 28, No. 4a. (Nov., 1995), pp. 836-857.

Stable URL:

http://links.jstor.org/sici?sici=0008-4085\%28199511\%2928\%3A4a\%3C836\%3AANR\%3E2.0.CO\%3B2-A

\section{Competition and Entry in Small Airline Markets}

Peter C. Reiss; Pablo T. Spiller

Journal of Law and Economics, Vol. 32, No. 2, Part 2, Empirical Approaches to Market Power: A Conference Sponsored by the University of Illinois and the Federal Trade Commission. (Oct., 1989), pp. S179-S202.

Stable URL:

http://links.jstor.org/sici?sici=0022-2186\%28198910\%2932\%3A2\%3CS179\%3ACAEISA\%3E2.0.CO\%3B2-C 